\title{
Diagnosis of Meckel's Diverticulum Using Colon Capsule Endoscopy for Small Bowel Investigation
}

We read with interest the case by Lee et al., ${ }^{1}$ describing congenital jejunal diverticular bleeding diagnosed with capsule endoscopy (CE) as a subepithelial tumor-like lesion in a young adult. There are few reports on the capsule endoscopic appearance of Meckel's diverticulum (MD) as a tumor-like lesion. ${ }^{2,3}$ The diagnosis of MD still represents a challenge, even with advances in technology. The reported diagnostic yield of CE for MD ranges between $7.7 \%$ and $35.7 \%{ }^{4.5}$ This low incidence is due to several factors. The classic endoscopic image of uncomplicated $\mathrm{MD}$ is reported as a double lumen with a blind end. As the capsule passes through the intestine via peristalsis without insufflation, the typical image of uncomplicated MD is rarely identified. ${ }^{6}$ Complicated MD, revealed by intermittent bleeding episodes, is the consequence of ectopic gastric mucosa, trauma, or inversion-induced ischemia. ${ }^{7.8} \mathrm{CE}$ might show ectopic gastric mucosa as an ulcer ${ }^{9}$ or a polypoid lesion inside a diverticulum..$^{10}$ An inverted bleeding MD generates even greater uncertainty on $\mathrm{CE}$, being confounded with a polyp or a bulging mass. ${ }^{2,3}$ In this context of a challenging diagnosis, can the accuracy of $\mathrm{CE}$ be improved to enable correct identification of MD?

We experienced a similar case in an 18-year-old patient who was referred for $\mathrm{CE}$ for obscure gastrointestinal bleeding (intermittent episodes of melena). The small bowel was investigated with a second generation PillCam colon CE. Compared to small bowel CE devices, the colon device has dual cameras, a better image acquisition rate (4-35 frames/second versus $2-6$ frames/second), and larger angle of view $\left(172^{\circ}\right.$ vs. $\left.156^{\circ}\right)$. "Manual" activation of second generation colon CE allows visualization of the entire gut in an adaptive frame rate mode. In our case, only one camera of the colon CE device revealed pathology: a circumferential polypoid mass, with small ulcerations on the superficial mucosa (Fig. 1). The patient was referred for surgery. MD was identified (Fig. 2) and removed with segmental ileal enterectomy. Histological analysis revealed ectopic gastric and pancreatic tissue in this small bowel diverticulum. At a six-month follow-up visit, the patient was in good clinical and biological condition.

These cases highlight the diagnostic challenge of $\mathrm{MD}$, even with use of $\mathrm{CE}$ and enteroscopy, which enable direct investigation of small bowel mucosa. The inverted MD in our case had both ectopic gastric and pancreatic tissue and presented

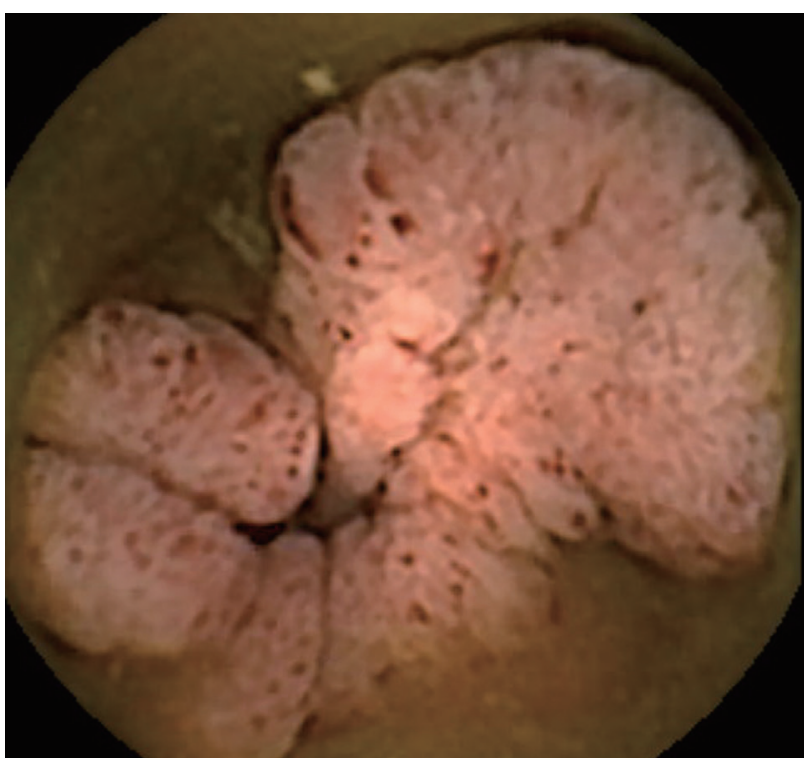

Fig. 1. Capsule endoscopy detected a circumferential polypoid mass, with small ulcerations on the superficial mucosa.

Received: December 1, 2017 Revised: January 15, 2018 Accepted: January 23, 2017

Correspondence: Lidia Ciobanu

University of Medicine and Pharmacy “Iuliu Hațieganu", Regional Institute of Gastroenterology and Hepatology, 19-21 Croitorilor Street, Cluj-Napoca 400162, Romania Tel: +40-745-042-155, Fax: +40-264-455-995, E-mail: ciobanulidia@yahoo.com

ORCID: https://orcid.org/0000-0002-9431-3950

(c) This is an Open Access article distributed under the terms of the Creative Commons Attribution Non-Commercial License (http://creativecommons.org/licenses/by$\mathrm{nc} / 3.0$ ) which permits unrestricted non-commercial use, distribution, and reproduction in any medium, provided the original work is properly cited. 


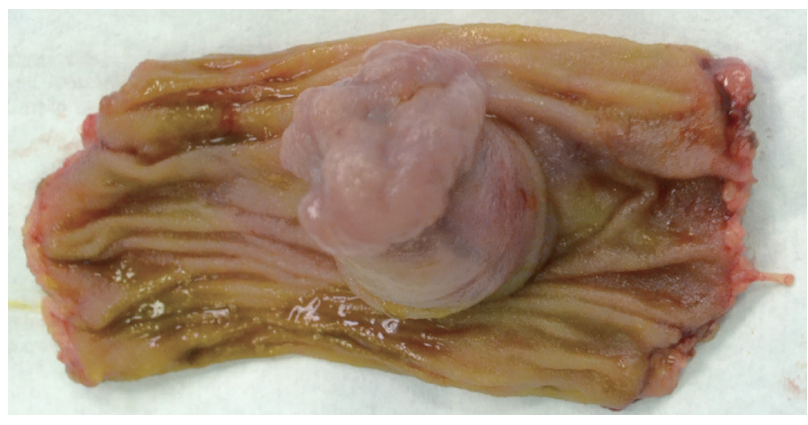

Fig. 2. The resected ileal segment with inverted Meckel's diverticulum resembling the capsule image.

with gastrointestinal bleeding. MD was only detected in one of two registrations on colon $\mathrm{CE}$, and was misinterpreted as a tumor.

Appearance as a polyp or tumor on CE was previously reported as corresponding to intussusception or the presence of ectopic gastric mucosa. ${ }^{1-3}$ As $\mathrm{MD}$ can be associated with carcinoid in $2 \%$ of patients, ${ }^{11}$ the differential diagnosis proves even more difficult. The literature argues for a more significant role of enteroscopy in the correct diagnosis of $\mathrm{MD}^{4,5} \mathrm{In}$ a report by $\mathrm{He}$ et al., ${ }^{4}$ the overall diagnostic yield of double-balloon enteroscopy was $84.6 \%$, i.e., significantly greater than that of $\mathrm{CE}$ at $7.7 \%$. In a study by Hong et al., the mean diagnostic accuracy of CE was $35.7 \%$ (14.0\%-64.4\%), compared with $85 \%$ for balloon-assisted enteroscopy. This important difference in diagnostic yield between enteroscopy and CE might be reduced by using colon $\mathrm{CE}$ for small bowel, which enables two simultaneous registrations and avoids missed lesions. Our case argues for this approach as the lesion was only detected only by one registration of the colon capsule and missed by the other. Technical improvements in colon CE might facilitate diagnosis in clinically suspected MD.

In conclusion, these cases reflect the variability of MD appearance and clinical manifestations, resulting in a challenging diagnosis. The use of colon CE for small bowel investiga- tion might be an alternative for MD diagnosis.

Conflicts of Interest

The authors have no financial conflicts of interest.

Lidia Ciobanu, Oliviu Pascu and Marcel Tanțău

University of Medicine and Pharmacy "Iuliu Hațieganu", Regional Institute of Gastroenterology and Hepatology, Cluj-Napoca,

Romania

\section{REFERENCES}

1. Lee JY, Jang JY, Kim MJ, Lee TI, Kim JW, Chang YW. Congenital jejunal diverticular bleeding in a young adult. Clin Endosc 2017;50:495-499.

2. Sy ED, Chen MD, Yang YJ, Shan YS. Obscure gastrointestinal bleeding due to Meckel's diverticulum: unusual capsule endoscopic finding as polyp-like lesion. Endoscopy 2008;40 Suppl 2:E203.

3. Kalla R, McGrath S, Campbell S. An unusual cause of gastrointestinal bleeding: there is more than meets the eye. Gastroenterology 2013;145:729, 915.

4. He Q, Zhang YL, Xiao B, Jiang B, Bai Y, Zhi FC. Double-balloon enteroscopy for diagnosis of Meckel's diverticulum: comparison with operative findings and capsule endoscopy. Surgery 2013;153:549-554.

5. Hong SN, Jang HJ, Ye BD, et al. Diagnosis of bleeding Meckel's diverticulum in adults. PLoS One 2016;11:e0162615.

6. Gölder S, Schmidt J, Kolmsee P, et al. Identification of a Meckel's diverticulum by wireless capsule endoscopy. Endoscopy 2005;37:608.

7. Rashid OM, Ku JK, Nagahashi M, Yamada A, Takabe K. Inverted Meckel's diverticulum as a cause of occult lower gastrointestinal hemorrhage. World J Gastroenterol 2012;18:6155-6159.

8. Karadeniz Cakmak G, Emre AU, Tascilar O, et al. Lipoma within inverted Meckel's diverticulum as a cause of recurrent partial intestinal obstruction and hemorrhage: a case report and review of literature. World J Gastroenterol 2007;13:1141-1143.

9. Montemaggi A, Paci M, Barp J, Milla M, Lionetti P. Circumferential peptic ulceration from Meckel diverticulum by capsule endoscopy. J Pediatr Gastroenterol Nutr 2012;54:1.

10. Mavrogenis G, Coumaros D, Bellocq JP, Leroy J. Detection of a polypoid lesion inside a Meckel's diverticulum using wireless capsule endoscopy. Endoscopy 2011;43 Suppl 2 UCTN:E115-E116.

11. Park JJ, Wolff BG, Tollefson MK, Walsh EE, Larson DR. Meckel diverticulum: the Mayo clinic experience with 1476 patients (1950-2002). Ann Surg 2005;241:529-533. 